\title{
Do national-level policies to promote low-carbon technology deployment pay off for the investor countries?
}

\author{
Gokul C. Iyer ${ }^{a^{*}}$, Leon E. Clarke ${ }^{a}$, James A. Edmonds ${ }^{a}$, Nathan E. Hultman ${ }^{\text {b }}$ \\ a Joint Global Change Research Institute, Pacific Northwest National Laboratory and University of \\ Maryland \\ ${ }^{\mathrm{b}}$ School of Public Policy, University of Maryland \\ * Corresponding author \\ Email-addresses: \\ gokul.iyer@pnnl.gov, leon.clarke@pnnl.gov,jae@pnnl.gov, hultman@umd.edu
}

\begin{abstract}
National-level policies to promote deployment of low-carbon technologies have been suggested and used as a means to reduce greenhouse gas emissions in the context of international climate change mitigation. The long-term benefits of such policies in the context of international climate change mitigation depend on their effects on near-term emissions abatement and resultant long-term technological change that will reduce abatement costs of achieving global mitigation goals. There is also an argument that these policies might foster early-mover advantages in international low-carbon technology markets. We first review the factors that could influence such benefits and use a global integrated assessment model to present an illustrative example to understand the potential magnitude of these benefits. We find that reductions in long-term abatement costs might not provide sufficient incentives to justify policies to promote the deployment of low-carbon technologies, in particular, the emerging, higher-risk, and currently expensive alternatives. We also find that early-mover advantages can potentially provide substantial benefits, but only if these advantages are both strong and persistent. Our results suggest a role for international cooperation in low-carbon technology deployment to address the existence of free-riding opportunities in the context of global climate change mitigation.
\end{abstract}

Keywords: Technological change; integrated assessment model; climate change; green; low carbon; spillover

\section{Introduction}

In the recent years, a number of countries have proposed or implemented deployment policies such as renewable portfolio standards, feed-in-tariffs, subsidies and tax incentives to promote the deployment of low-carbon technologies at the national level (IEA, 2009; OECD, 2011). An important justification for these policies has often been their contribution to national strategies to reduce greenhouse gas (GHG) emissions. For example, China's intended nationally determined contribution (INDC) outlining 
greenhouse gas mitigation action for the near-term includes a commitment to increase the share of nonfossil energy sources in primary energy to $20 \%$ by 2030 (UNFCCC, 2015). Likewise, India has committed to ramp up the share of non-fossil-based power capacity from $30 \%$ currently to about $40 \%$ by 2030. These proposals are natural extensions of continuing investments in low-carbon technologies motivated by a diverse set of policy goals including energy security, air pollution reduction, domestic industry, and climate mitigation. For example, in the U.S.A., clean energy was the focus of more than $\$ 90$ billion in government investment and tax incentives in the American Recovery and Reinvestment Act (ARRA) of 2009, which is an economic stimulus package in response to the global financial crisis of 2008-2009 (Council of Economic Advisers, 2014). Likewise, China's $12^{\text {th }}$ Five-year Plan announced investments of US\$ 468 billion in "greening" key economic sectors, with a focus on waste recycling, clean technologies and renewable energy (UNEP, 2015).

A key question for public policy is whether investments in national-level policies to promote the deployment of low-carbon technologies might pay off in the long-term for the investor countries. In this paper, we focus on the benefits of such investments in the context of global climate change mitigation. In particular, we assess two long-term domestic benefits (Figure 1) ${ }^{1}$. First, because these policies lead to emissions abatement in the near-term, they can ease the future burden of emissions abatement associated with meeting any fixed climate goal, such as a $\mathrm{CO}_{2} \mathrm{e}$ concentration goal or a cumulative emissions budget of achieving a stringent long-term climate goal such as limiting temperature change to $2^{\circ} \mathrm{C}$ this century (IPCC, 2014; Iyer et al., 2015d). Additionally, promoting the deployment of low-carbon technologies could induce technological change in the long-term in the targeted technologies. Thus, long-term emissions abatement can be achieved at lower costs (Goulder and Mathai, 2000; Schneider and Goulder, 1997). We refer to this as "reduced long-term abatement costs".

Second, investing in policies to promote the deployment of low-carbon technologies could give rise to comparative advantages and increased competitiveness for domestic industries in international markets, leading to an expansion of export industries and international leadership in low-carbon technology markets. International mitigation has an important role to play in this context, because it will increase the international market size for low-carbon technologies as emissions are reduced over time. We refer to this as "early-mover advantages" (Bowen and Fankhauser, 2011; Fankhauser et al., 2013; Karp and Stevenson, 2012; Lieberman and Montgomery, 1988).

\footnotetext{
${ }^{1}$ An emerging literature on "co-benefits" discusses a variety of other benefits of such investments such as energy security, improved air quality and improved health (von Stechow et al., 2015). A detailed examination of such benefits is beyond the scope of this paper.
} 
We answer our question by first reviewing the literature on the reduced abatement cost and the earlymover advantage benefits of near-term policies to promote the deployment of low-carbon technologies (referred to as low-carbon deployment policies or simply, deployment policies in the rest of the paper). We then discuss the factors that could influence the magnitudes of these benefits. Following this, we use a global integrated assessment model (Global Change Assessment Model; GCAM) to present an illustrative example to understand the long-term benefits of near-term low-carbon deployment policies. Our example builds off Iyer et al. (2015b) that analyzed the long-term benefits of near-term low-carbon deployment policies in the context of climate change mitigation from a global perspective. Iyer et al. (2015b) demonstrated the divergence in domestic and global outcomes when countries promote the deployment of low-carbon technologies in the near-term based on domestic benefits alone. The current study differs from Iyer et al. (2015b) in that we focus on domestic long-term benefits.

\section{Overview of the long-term benefits of near-term low-carbon deployment policies}

\subsection{Reduced long-term abatement costs}

Promoting the deployment of low-carbon technologies could lead to reduced costs of emissions abatement in the long-term through two effects. First, these policies will lead to near-term emissions abatement by avoiding lock-in into carbon intensive fossil fuel technologies. The policies would displace fossil fuel technologies and add low-carbon energy to the energy system, leading to emissions abatement. Thus, if, in the long-term, there is global action against climate change to achieve a climate target such as a $\mathrm{CO}_{2} \mathrm{e}$ concentration goal or a cumulative emissions budget to limit global warming to $2{ }^{\circ} \mathrm{C}$ (IPCC, 2014), abatement in the near-term would result in lower abatement in the long-term, resulting in reduced long-term abatement costs.

Second, promoting the deployment of low-carbon technologies could induce technological change in the targeted technologies in the long-term. Accumulating experience with a technology is known to lead to technological improvements, for example via experience-driven refinements in the production process, which can also be supported by a number of forces such as increases in labor efficiency, new processes and changes in production methods (Arrow, 1962). Such improvements could also be facilitated by users' experience feeding back as sources of learning and further R\&D and tacit learning through exchange of information between various stakeholders (Kahouli-Brahmi, 2008). Thus, promoting the deployment of low-carbon technologies could generate cheaper technological options and future emissions abatement can be achieved at reduced costs (Goulder and Mathai, 2000; Grubb, 1997; Grübler and Messner, 1998; Schneider and Goulder, 1997). 


\subsection{Early-mover advantages}

A commonly cited benefit of low-carbon deployment policies is that the improvements in technology due to these policies could lead to increases in productivity resulting in comparative advantages and increased international competitiveness of domestic firms. This could create "early-mover advantages" in what is being suggested as a global "green race" similar to the "space race" of the 1950's (Eisen, 2011; Fankhauser et al., 2013; Galiana and Green, 2009; The PEW Charitable Trusts, 2015; Voituriez and Balmer, 2012). ${ }^{2}$

The early-mover advantage benefit could take two forms. First, the improved international competitiveness could create opportunities to expand export industries (Fankhauser et al., 2013; Krugman, 1987). Countries are typically willing to increase exports under the belief that knowledge flows from international buyers and competitors help to improve the performance of exporting firms. Furthermore, firms participating in international markets are exposed to more intense competition and must improve faster than firms that are exposed to domestic markets alone. Hence exporting firms tend to be more productive (Bernard et al., 1995). In addition, exporting is expected to generate positive externalities for other economic activities, resulting in overall economic growth (Rodrik, 2006). In the context of low-carbon technologies, this argument is often known as "green growth" (Bowen and Fankhauser, 2011; Karp and Stevenson, 2012).

Second, expansion of low-carbon industries could also create direct or indirect domestic employment opportunities. Examples of direct jobs include those in planning, production and installation of wind turbines and PV modules or fuel supply (e.g. cultivating and harvesting feedstock for bioenergy) and operations and maintenance. Indirect jobs include those in upstream industries such as manufacturing (e.g. steel, electronics and plastics) (IRENA, 2014a; Lehr et al., 2012). Studies have shown that lowcarbon technologies such as renewables generate more jobs per unit of installed capacity compared to fossil fuels (Kammen et al., 2004; UNEP, 2008).

A classic example of some of the above advantages in the energy industry is that of the wind industry of Denmark. Since the 1980's, Danish energy policy focused on promoting wind (then an infant industry)

\footnotetext{
${ }^{2}$ In their seminal work, Lieberman and Montgomery (1988) describe three ways by which "early-mover advantages" arise at the level of the firm. First, experience could lead to technological improvements and if this can be kept proprietary, for example, through intellectual property rights, it could generate a cost advantage for the early entrant and the firm can maintain leadership in market share. Second, there may be buyer switching costs that might stem from initial transactions costs or investments that the buyer makes in adapting to the seller's product or contractual switching costs that may be intentionally created by the seller. Third, early-mover firms may be able to establish a reputation for quality and late entrants must have a truly superior product. In such cases, the returns garnered by the early-moving firms are pure economic rents- especially if other firms are bound to the above factors by switching costs.
} 
domestically and by 2003, Danish wind turbine manufacturers supplied more than half of the global demand for wind turbines and Denmark enjoyed an expanding export industry (Hansen et al., 2003). Another example is the expanding PV industry of China - not only is China one of the top three markets for PV, Chinese manufacturers are also leading exporters of PV modules (REN21, 2015).

Other important benefits of low-carbon deployment policies include energy security and health benefits due to avoided air pollution (Clarke et al., 2014; von Stechow et al., 2015). While these are important benefits to be included in a comprehensive reckoning of national actions, our discussion here focuses only on the reduced long-term abatement costs and early-mover advantage benefits, reserving a detailed treatment of other benefits for future work.

\section{Factors influencing long-term benefits of near-term low-carbon deployment policies}

A wide range of factors influence the long-term benefits of a near-term low-carbon technology investment strategy, either by altering technological change or near-term abatement, or by influencing the benefits directly. Here we discuss four such sets of factors: i) the potential for technological change in the targeted technology, ii.) the rate and direction of technological change, iii.) public goods characteristics of emissions abatement and technological change and iv.) factors that directly influence the magnitude of early-mover advantages (Table 1). Our review suggests that although there are opportunities for near-term low-carbon deployment strategies to pay off for the investor countries in the long-term, the magnitudes of the long-term benefits could be influenced by complex interactions among a variety of country, sector or even technology specific factors.

\subsection{Factors influencing the potential for technological change}

One of the key effects of near-term deployment policies leading to long-term benefits from reduced abatement costs as well as early-mover advantages is technological change (Figure 1). By extension, the magnitudes of long-term benefits of near-term low-carbon deployment policies would depend on the potential for future technological change which in turn depends on how mature the targeted technology is in domestic as well as global markets. This is because, technological knowledge exhibits diminishing returns to scale (Arrow, 1962). In other words, the potential for rapid technological improvements will decrease as technologies gain maturity since mature technologies would have a vast stock of existing knowledge. Hence, the scope for technological change in relatively mature technologies would be lesser compared to newer alternatives. Thus, if a country were to promote the deployment of a currently mature technology with limited scope for future technological improvements compared to currently immature alternatives, long-term benefits from reduced long-term abatement costs as well as early-mover advantages can be expected to be lower. 


\subsection{Factors influencing the rate and direction of technological change}

The magnitudes of the long-term benefits would depend on the rate and direction of technological change: long-term benefits would be higher if a near-term deployment policy results in decreases rather than increases in the costs of the targeted technology and if the rate of improvement in technology costs is higher. Some of the factors influencing the rate and direction of technological change are discussed below.

\section{Amount of near-term deployment}

One of the important factors influencing the rate and direction of technological change is accumulating experience (Arrow, 1962). Greater near-term deployment would lead to greater experience with the technology, resulting in faster improvements in the technology. Thus, long-term benefits from reduced abatement costs and early-mover advantages will be greater with greater near-term deployments.

\section{Technological spillovers}

The rate and direction of technological change could be influenced by technological spillovers originating from firms, industries or countries external to the domain of the targeted technology and their interactions with the targeted technology (Clarke et al., 2008). For example, Nemet (2006) examined the capital costs of PV modules manufactured from mono-crystalline and poly-crystalline silicon wafers and found that during the period from 1980 to 2001, spillovers from manufacturing improvements in the microprocessor industry, one of the main customers of silicon producers with high purity standards at the time were important drivers of cost reductions in PV modules.

In addition, the presence and use of general purpose technologies (GPTs) such as semiconductors and computers across applications could create technological opportunities that might be exploited across a range of industries (Bresnahan, 2010; Bresnahan and Trajtenberg, 1995). GPTs are characterized by pervasive and diffusive use in a wide range of sectors throughout the economy, rapid technological change, and their ability to enable innovation in downstream application sectors.

\section{Market forces}

The rate of technological change could also be influenced by market forces. For example, in the early 1970's, the U.S. space program, accounted for almost all of the sales of PV, resulting in a monopsony market. Nemet (2006) observed that during 1975 to 1979, terrestrial applications of PV overtook spacebased satellite applications as the dominant end use. This shift led to a reduction in the quality of PV modules as it rendered certain characteristics such as module efficiency and lifetime unimportant, 
allowing manufacturers to switch to less costly processes. ${ }^{3}$ This change in the market for PV also affected prices because of the difference in the demand elasticities of the two types of end-users and increasing competition in terrestrial markets.

\section{Impact of deployment policies on innovation}

The rate of technological change induced by deployment policies would also depend on the extent to which the policies influence innovation. Deployment policies such as subsidies are known to create disincentives for innovative activity. For example, Nemet (2009) explored the effect of deployment policies such as investment tax credits, production tax credits, guaranteed tariffs, and renewable portfolio standards that were prevalent in California between 1975 to 1991 on innovation, using data on patents filed on wind power during the study period. The study found that, during this period, although demand for wind power increased due the policies, patenting activity declined among other reasons, because of the lock-in of a dominant turbine design and limited market opportunity for advanced technology. During the study period, the three-blade, horizontal axis, upwind design became the preferred wind turbine design (that continues to dominate the wind industry even today) although it was not clear at the time whether this design was the best. ${ }^{4}$ This suggests that deployment policies to promote currently existing technologies could potentially lead to a lock-in of inferior technologies, influencing long-term benefits of deployment policies.

Along similar lines, Hoppmann et al. (2013) conducted comparative case studies on firms in the PV industry in Japan, China and Germany and concluded that deployment policies discourage firms pursuing relatively mature PV technologies such as wafer-based crystalline silicon PV to innovate and create market barriers for firms pursuing newer alternatives such as thin-film, organic and dye-sensitized varieties with significant potential for technological improvements.

\footnotetext{
${ }^{3}$ The transition from space-based applications to terrestrial applications allowed the use of cheaper materials and less robust assembly processes resulting in less costly manufacturing. For example, spatial and weight constraints in space satellite applications required PV modules to maximize watts delivered per $\mathrm{m}^{2}$. With the shift toward terrestrial applications, manufacturers could use the entire area of the silicon wafer including the portions near the edges which have high electrical resistance. Also, manufacturers could use less expensive chemical polish to enhance light transmission through the glass cover, rather than the ground optical finish that was required for satellites. In addition, terrestrial applications could be useful with shorter module lifetimes as opposed to satellite programs that required reliable operation over 20 -year time periods. Indeed, Nemet observed a decline in average industry module lifetime during the late 1970s.

${ }^{4}$ Other wind turbine designs might have advantages. For example, vertical axis turbines do not require a yaw system to rotate to face the wind, the drive train is conveniently accessible at ground level and are typically less noisy because of lower tip-speed ratios.
} 


\section{Stability of policy incentives}

A policy that does not provide steady incentives may influence the rate and direction of technological change. This is because, technological knowledge, particularly that gained out of accumulating experience, is short-lived and depreciates with time because such knowledge often remains uncodified, resides in individuals (e.g., staff) or organizational entities (e.g., management) and needs to be acquired again in case of staff turnover. Knowledge depreciation rates of between $10 \%$ per year (wind turbines) and 30\% per year (PV) have been identified in the literature. Higher depreciation rates of up to $100 \%$ per year have been observed in service industries (Grubler and Nemet, 2012).

\section{Other factors}

The rate and direction of technological change could be influenced by institutional factors. For example, a conducive institutional setting that allowed centralized decision-making, regulatory stability, dedicated efforts for standardized reactor designs, and a powerful nationalized utility enabled the successful scalingup of pressurized water reactors (PWRs) in France. ${ }^{5}$ Between the early 1970's and 2000, 58 PWRs (with a gross capacity of $66 \mathrm{GW}$ ) were built, accounting for about $80 \%$ of France's electricity production. In spite of this scaling up, specific investment costs during this period increased (rather than decrease) by a factor of 2.5. Grübler (2010) explained this "negative learning” to be a consequence of increased complexity of reactors in both construction and operation during the study period that made standardization difficult; and increased construction times due to increased size and increased environmental, health and safety regulations. Similar findings were reported by Koomey and Hultman (2007) for reactors in the U.S.A.

Finally, the literature on industrial policy cautions against targeting specific industries because that could give rise to institutional challenges by encouraging rent-seeking behavior and corruption (Ades and Tella, 1997; Krueger, 1974; Rodrik, 2006). An example is the recent corruption scandal involving the major Brazilian oil company Petrobras which was hailed as a "national champion" (The Economist, 2015). Such institutional challenges could adversely affect innovative activity and overall investment (for example, by reducing investors' confidence); thereby influencing the rate and direction of technological change induced by deployment policies (Iyer et al., 2015a; Iyer et al., 2015c).

\footnotetext{
${ }^{5}$ The Électricité de France acts as the principal (the electric utility) as well as the agent (the engineering or construction firm) with the institutional capacity of thousands of engineers to engineer and manage construction projects. This was instrumental in reducing construction times and moderating cost inflation during the initial phase of the French nuclear program.
} 


\subsection{Public goods characteristics of emissions abatement and technological change}

Near-term emissions abatement and long-term technological change due low-carbon deployment policies have public goods characteristics and these might influence long-term benefits of low-carbon deployment policies. Near-term emissions abatement is a public good because GHGs are well mixed (that is, they have lifetimes long enough to be relatively homogeneously mixed in the troposphere). Consequently, any abatement achieved by a domestic deployment policy also applies to the globe. Likewise, technological change that occurs domestically due to a domestic deployment policy may spill over to firms globally, representing a public good.

The public goods characteristics of near-term emissions abatement and long-term technological change might have two counteracting effects on the long-term benefits of near-term low-carbon deployment policies. The first effect is that they create opportunities to free-ride; since a country could benefit from technology deployment efforts undertaken internationally. As we will discuss using our example in Sections 4 and 5, such opportunities could dampen the incentives that reduced long-term abatement costs could potentially provide to undertake near-term investments in low-carbon technologies, in particular, the emerging and currently expensive alternatives (Iyer et al., 2015b). Likewise, such opportunities could also dampen the early-mover advantage benefit by creating incentives to wait and free-ride on efforts undertaken internationally and being "late-movers" instead of early-movers (Fudenberg and Tirole, 1985; Hoppe, 2000).

The second effect is to lower the marginal cost of long-term emissions abatement globally, for example, by making cheaper technologies available globally through technological spillovers. This would in turn induce greater emissions reductions by the rest of the world, and thereby reduce the level of effort needed in the investor country in the long-term to achieve a long-term global climate target. This indirect effect would ultimately lower the long-term abatement costs for the investor country and thus increase the benefit from reduced long-term abatement costs (Clarke et al., 2010; Milliman and Prince, 1989).

It is important to note that while the public goods characteristics of emissions abatement is well established, there is ambiguity surrounding the nature of spillovers, particularly those occurring across national borders. Research has shown that the appropriation of international spillovers by domestic firms

might be costly and limited by institutional, political and even cultural factors (Clarke and Weyant, 2002). In a recent study, Braun et al. (2010) used patent data for 21 OECD countries to show that innovation in wind and solar technologies is strongly driven by knowledge spillovers. However, the study also found that the influence of international spillovers on technology costs is insignificant. One explanation for this is that the pool of knowledge available domestically may be large enough that acquiring foreign 
knowledge is redundant. Another more plausible explanation could be that appropriation of foreign knowledge is more expensive compared to domestic knowledge. Therefore, in our illustrative example in Sections 4 and 5, we present scenarios with varying levels of international spillovers to understand their potential implications for long-term benefits of near-term low-carbon deployment policies.

\subsection{Factors directly influencing the magnitude of early-mover advantages}

The early-mover advantage benefit of near-term deployment policies depends on the technological change effect (Figure 1) and by extension, on the factors influencing the nature of technological change reviewed above. Apart from those factors, early-mover advantages could be influenced by existing capabilities, emergence of international competitors, dependence of domestic firms on policy support, selection effects among exporting firms and uncertainty in the net welfare impacts of deployment policies. Taken together, these factors create large uncertainties in the presence and magnitude of early-mover advantages.

\section{Existing capabilities}

The key to the early-mover advantage benefit is the ability of the investor country investing in low-carbon deployment policies to create comparative advantages in the markets for the targeted technology. Research has shown that comparative advantages in goods derive out of existing capabilities in related sectors (e.g. skills, capital, knowledge and institutions) (Hidalgo et al., 2007). For example, Denmark was an expert in high-precision machine goods and found the move into wind turbines relatively easy (Huberty et al., 2011). However, countries without essential capabilities may not and hence, early-mover advantages might not be generally applicable.

\section{Emergence of international competitors}

Early-mover advantages might get completely dissipated under preemptive adoption as competitors enter the market. For example, while Danish wind turbine manufacturers supplied more than half of the global demand for wind turbines in 2003, with the entry of competing firms in other European countries and developing countries such as India, market shares fell to less than 15\% in 2015 (REN21, 2015).

\section{Other factors}

Other factors influencing the early-mover advantage benefit include the dependence of domestic firms on policy support and the uncertain effects of deployment policies on exports and employment. It is important to understand how dependent firms are on public policy support as that would decide the nature of repercussions for those industries and the economy as a whole, if, for some reason, government support is terminated (Victor and Yanosek, 2011). For instance, in 2008, Spain accounted for the largest share of 
solar generation in the world, but its manufacturing and installation of new capacity virtually disappeared in 2009 when subsidies were cut off (Borenstein, 2012). Likewise, production tax credits in the U.S. are allowed to expire intermittently and are known to cause cycles of layoffs and rapid hiring (Barradale, 2010; REN21, 2015).

A key source of economic benefits of low-carbon technology deployment is the potential for future exports and the resulting economic benefits. An important argument in this regard is that exporting firms tend to be more productive; hence a booming exports industry would spur economic growth through overall increases in productivity. Although there is not much evidence from the low-carbon industry, empirical research from the manufacturing sector suggests that exporting might have only a weak correlation with productivity or firm performance. Rather, it is often better firms that are able to or choose to export because additional sunk costs of selling goods in foreign countries such as transportation costs, distribution or marketing costs, need for skilled personnel and production costs in modifying current domestic products for foreign consumption create an entry barrier that smaller or less productive firms might not be able to overcome (Wagner, 2007). Therefore, promoting exports through policy may not necessarily enhance overall productivity or technological capacity (Rodrik, 2006).

Another source of economic benefits of low-carbon technology deployment is the increase in gross employment, for example, by creating jobs in planning, production and installation. However, the net employment and welfare impacts on the economy are not well understood. For instance, deployment policies could crowd out investment in fossil fuel technologies leading to job losses in those sectors. In addition, such policies could translate into higher energy prices, adversely affecting competitiveness of energy-intensive industries, which could further lead to a contraction of economic activity in terms of lower consumption and profit or investment (Blazejczak et al., 2014; Lehr et al., 2012). Studies on the overall effects of low-carbon deployment policies on jobs suggest both negative (Böhringer et al., 2013) as well as positive (Blazejczak et al., 2014; Lehr et al., 2012) effects, with results depending on assumptions about labor market conditions ${ }^{6}$, trade, effects of the deployment policies on innovation, stringency of the policy (e.g. subsidy rate) and the financing mechanism (e.g. labor tax versus electricity $\operatorname{tax})$.

\footnotetext{
${ }^{6}$ For e.g., if labor markets are rigid, and additional workers cannot be easily mobilized from the pool of unemployed, Blazejczak et al. (2014) observed that additional production can be achieved through increase in productivity. In this case, the authors found that the net employment effect is small, but positive. However, if labor markets are more flexible, the net employment effects were found to be substantial.
} 
Furthermore, employment effects over time are confounded by the potential for mechanization. For example, most of the jobs created by promoting the deployment of biofuels would be in the agricultural sector, in cultivating and harvesting feedstock. As feedstock harvesting gets mechanized, the number of people employed in these positions may shrink over time. These effects are already occurring in Brazil (IRENA, 2014a). A complete assessment of the employment effects of promoting low-carbon technology deployment is further complicated by the lack of clear understanding of the quality of jobs created and the degree to which skills of potential workers match the requirements of such jobs (Lambert and Silva, 2012).

\section{Illustrative example}

\subsection{The Global Change Assessment Model}

To gain a deeper understanding of the long-term benefits of near-term low-carbon deployment policies, we create an illustrative example using the Global Change Assessment Model (GCAM). A detailed description of GCAM is available in the GCAM wiki and the below description is a summary (GCAMwiki).

GCAM combines models of the global energy, economy, land use, and climate systems (Edmonds et al., 2004; Edmonds and Reilly, 1985; Kim et al., 2006; Sands and Leimbach, 2003). The climate system is represented by the Model for the Assessment of Greenhouse-Gas Induced Climate Change (MAGICC) (Meinshausen et al., 2011; Wigley, 2008; Wigley and Raper, 1992). Outcomes of GCAM are driven by assumptions about population growth, labor participation rates, labor productivity, technology, and policy in fourteen geo-political regions. The version of GCAM used in this study (GCAM 3.2) uses a 5-year time step, initialized to 2005 with a time horizon of 2095. GCAM is a dynamic-recursive model and solves for the equilibrium prices and quantities in all energy, agricultural and GHG markets in each time period and in each region. GCAM tracks emissions for sixteen GHGs that are determined endogenously based on the resulting energy, agriculture, and land use systems. GHG concentrations, radiative forcing, and global temperature change are determined using MAGICC.

The energy system in GCAM comprises of representations of depletable primary resources such as coal, natural gas, oil and uranium along with renewable sources such as solar and wind (at regional levels) that are transformed into final energy carriers (such as, electricity and hydrogen), which ultimately provide energy services to end users. GCAM is a technology-rich model and contains detailed representations of technology options in all of the economic components of the system. Individual technologies compete for market share based on their technology characteristics (efficiency in the production of products from inputs), and cost of inputs and price of outputs. The efficiency of a technology determines the amount of 
fuel required to produce each unit of output. The prices of fuels are calculated endogenously in each time period based on supplies, demands, and resource depletion. The depletion of economically available energy resources is explicitly tracked throughout the modelling period. The deployment of technologies in GCAM depends on relative costs and is achieved using a logit-choice formulation that represents decision making among competing options when only some characteristics of the options can be observed (Clarke and Edmonds, 1993; McFadden, 1980; Train, 1993).

It is important to note that our research question and the methodology employed to address the question differ from previous studies on the benefits of low-carbon deployment policies in at least three ways. First, previous studies on the benefits of near-term low-carbon deployment policies focus on the immediate impacts of such policies on the timescale of a few years. Such studies use techniques such as multi-criteria analyses (IRENA, 2014b) and indicator-based approaches (Mundaca and Luth Richter, 2015 ) to assess the implications of low-carbon deployment policies on a range of variables such as electricity generation, emissions and employment. In contrast, our study focuses on the long-term implications of near-term low-carbon deployment policies on the timescale of decades. GCAM is wellsuited for this purpose since it runs through the end of the $21^{\text {st }}$ century. Second, while the above studies evaluate the impacts of policies at the national and sub-national levels, our study aims to capture international effects as well. GCAM is well-suited to address this purpose because its scope is global with representations of energy, economic, agricultural and land-use systems for fourteen geopolitical regions (some of which are individual countries, for example, China and the U.S.A.) and the global climate all under one consistent framework. Thus, GCAM enables us to link national effects of deployment policies, for e.g. on national GHG emissions reductions to global climate and thus track the interactions between national and international policies. Third, while the above studies are ex-post evaluations of particular policies, the aim of our analysis is not to represent any particular real-world policy, but rather to illustrate, by means of an example, some key factors that influence whether or not near-term national-level investments in low-carbon technologies pay off for the investor countries in the long-term.

\subsection{Description of the example and scenarios using GCAM}

We consider a hypothetical example along the lines of (Iyer et al., 2015b) (Table 2). In this example, China has the option to either promote wind or solar technologies in the near-term (2016-2030) by means of deployment policies. The selection of wind and solar technologies for the example is intended to illustrate differences in market maturities of the technologies as well as differences in the potential size of 
future global markets. In the example, the relatively cheaper and mature technology is wind while solar is the relatively immature and expensive technology. ${ }^{7}$

Near-term deployment policies are modeled as renewable portfolio standards to achieve an installed capacity of the targeted technology of $500 \mathrm{GW}$ by 2030 . The $500 \mathrm{GW}$ assumption is roughly consistent with a $20 \%$ share of non-fossil energy in primary energy consumption across scenarios explored in this study. The $20 \%$ target was recently announced by the Chinese government as China's intended nationally determined contribution, in preparation for the $21^{\text {st }}$ Conference of Parties (UNFCCC, 2015). ${ }^{8}$ After 2030, we assume that all countries undertake a coordinated effort to achieve a global $\mathrm{CO}_{2} \mathrm{e}$ concentration by 2100 of 550 ppmv.

An important issue to consider is that the near-term abatement and technological change effects have public goods characteristics. Hence, long-term benefits of China's deployment policies will depend on low-carbon deployment strategies undertaken internationally. In order to understand this effect, we assume that the U.S.A. also has the option of promoting the deployment of wind or solar technologies in the near-term. ${ }^{9}$ For simplicity in illustrating the key dynamics in play, we assume that no other country undertakes deployment policies or emissions mitigation policies during this period. In order to make the different deployment policy configurations comparable, we fix the near-term and long-term policy mechanisms and stringency levels across all deployment policy configurations. ${ }^{10}$

The deployment policies will lead to emissions abatement in the near-term and could also induce technological change in the long-term. We consider four technological change and spillover scenarios to study the technological change effect (Table 3). The first is the counterfactual scenario in which deployment policies do not lead to any additional improvements in technology costs (the "No additional

\footnotetext{
${ }^{7}$ Wind is expected to remain less expensive than solar in the near-term. For instance, the EIA estimates levelized costs of \$73/MWh, \$114/MWh and \$221/MWh respectively for wind, solar PV and solar thermal plants entering service in 2020.

${ }^{8}$ Note that we do not evaluate specific deployment policies. Instead, we focus on illustrating how the choice of technology in the near-term could influence long-term payoffs. We therefore fix the policy mechanism as well as stringency across deployment policy configurations to enhance comparability. See Supplementary information for a sensitivity analysis on the stringency of the near-term deployment policy.

${ }^{9}$ The selection of U.S.A. for the example is based not only on relevance to recent policy discussions, but also differences in expected near-term energy system characteristics in the absence of any targeted deployment policy with China. For example, China's energy system is dominated by coal and is expected to grow in the near-term. In contrast, gas and oil account for a significant share in the energy mix of USA, in addition to coal and the energy system is expected to remain relatively stable (Figure SI-2).

${ }^{10}$ It is important to note that we do not consider the case where countries can diversify their low-carbon technology investment strategies. This might seemingly limit the scope of the analysis since in reality, countries might diversify their deployment strategies. Our hypothetical example is intended to clearly illustrate some of the key dynamics that influence long-term benefits of near-term low-carbon deployment policies rather than to precisely replicate realworld situations.
} 
technological change" scenario). In this scenario, regions with and without deployment policies receive "reference" technologies, whose costs reduce at "reference" rates, as we explain shortly. In the second scenario, deployment policies lead to faster improvements in technology costs (corresponding to "advanced" technologies whose costs reduce at rates greater than "reference" technologies) only in the country that invests in the deployment policy (the "Faster domestic improvements" scenario). In the third and fourth scenarios, technological improvements spill over to other countries either after some period of delay beyond 2030 (the "Faster domestic improvements and delayed spillovers" scenario) or immediately in 2030 (the "Faster domestic improvements and immediate spillovers" scenario).

We consider two scenarios to study the effect of the rate of technological change. Our central assumptions about the rates of improvements of reference and advanced wind and solar technologies presented in Table 3 are consistent with Clarke et al. (2007) and McJeon et al. (2011) (Figure SI-1, Table SI-1). In these central assumptions, wind technologies are cheaper than solar throughout the century. Although wind is the more cost-competitive technology at present, projections agree that solar technologies offer more opportunities for further cost reductions. For example, Black \& Veatch (2012) project that wind capital cost will remain constant through 2050 while utility-scale solar PV capital cost will decline by almost 50\%. Likewise, Anadon et al. (2011) forecast a 60\% reduction in solar PV module cost by 2030, with even lower costs possible under increased RD\&D investment. To address the possibility that solar technologies might experience a step-change in costs with sufficient investment, we consider a "solar breakthrough" case. In this case, promoting solar in the near-term leads to a technological breakthrough in solar technologies such that costs of solar technologies drop to one-fourth that of wind by 2050 and rapidly decrease thereafter.

The final variable across scenarios is the degree to which investor countries investing in near-term lowcarbon deployment policies can take advantage of early-mover advantages. In this study, early-mover advantages are assumed to be equal to a fraction of the global market revenue generated by the sales of the targeted technology across the globe. We explore the variability in early-mover advantages in a highly parameterized fashion by varying the fraction of the global market revenue that can be captured as rents by the investor country as well as the number of years for which such advantages exist.

It is important to note that GCAM is a deterministic model. The long-term perspective in this study demands modeling of human systems over long timeframes and any such modeling exercise would invariably carry with it considerable uncertainty. A formal probabilistic analysis would therefore be the ideal approach. In contrast, we explore a broad range of scenarios without a formal treatment of likelihood or uncertainty, not only to outline the range of outcomes but also to examine the various factors 
influencing long-term payoffs of near-term low-carbon deployment policies. While formal uncertainty analysis has much to offer and could be a useful direction for future research, our approach is aimed at illustrating, albeit incompletely, the range of possibilities and the various effects at play.

\subsection{Calculating long-term payoffs}

We calculate near-term costs of the deployment policies as the change in both consumer and producer surplus due to the policy. The long-term benefits are then the sum of reduced abatement costs and of benefits from early mover advantages. We calculate long-term benefits from reduced abatement costs as the reduction in abatement costs borne by the individual country (calculated as the area under the marginal abatement cost curve) relative to the case without any deployment policy. Early-mover advantages are approximated as a fraction of the global market revenue generated by the sales of the targeted technology across the globe. This is an admittedly simplistic, ad hoc assumption that hides much of the complexity associated with early-mover advantages. The purpose here is not to replicate the nature of early-mover advantages but rather to explore how big they would have to be in monetary terms to justify near-term low-carbon deployment policies.

Finally, to compare different deployment policy configurations, we define "long-term payoffs" as follows and explore the conditions under which the payoffs are greater than one.

Long-term Payoff $=\quad \frac{\begin{array}{c}\text { Reduction in long-term } \\ \text { abatement costs due to } \\ \text { deployment policy }\end{array}}{\text { Near-term cost of deployment policy }}$

\section{$5 \quad$ Results and discussion}

\subsection{Near-term costs of low-carbon deployment policies}

Without any deployment policies, near-term deployment of wind is more than solar in China as well as the U.S.A. because wind is relatively more mature and cheaper - hence more competitive - compared to solar (Table 4). Under deployment policies, fossil fuel energy sources are replaced with low-carbon sources, leading to near-term emissions abatement (Table 4). A solar policy leads to greater near-term abatement compared to a wind policy in both countries because a solar policy adds more low-carbon energy to the system (note that both, wind and solar policies are modeled to achieve the same cumulative capacities of wind and solar respectively through 2030 and since there is lesser solar to begin with, the low-carbon energy added to the energy system by the solar policy is greater than the wind policy). In addition, since solar technologies are more expensive than wind, the economic costs of a solar policy are 
higher. In our model, the near-term costs of a solar policy for China are more than five times that of a wind policy.

\subsection{Long-term payoffs from reduced abatement costs alone}

We first explore long-term benefits of near-term low-carbon deployment policies accruing from reduced long-term abatement costs (Figure 2). In the scenarios in which the low-carbon deployment policies do not lead to further advances in technology, China's long-term payoffs are less than one irrespective of the choice of technology by the U.S. In general, payoffs are lower for a solar policy, because such policies have substantially higher near-term costs.

The long-term payoffs increase in the presence of technological change and spillovers. Indeed, China's payoffs are higher even in the case where Chinese technology spills over to other countries rather than vice versa. This is because of the indirect effect of the public goods characteristics of near-term emissions abatement and long-term technological change on future marginal abatement costs explained earlier. In these scenarios, improved technologies due to the near-term deployment policies are available globally. This induces higher emissions abatement in the rest of the world leading to lower emissions abatement in China to achieve the 550 ppmv $\mathrm{CO}_{2} \mathrm{e}$ goal.

However, opportunities to free-ride appear to be the most important: the only circumstance in which China has a payoff greater than one is the situation in which it invests in wind, the relatively cheaper technology and free-rides on the near-term abatement as well as technological improvements that spill over due to U.S. investments in solar, the more expensive alternative. This is an important point, because it highlights the lack of incentives to undertake unilateral investments, in particular, in expensive technologies, in the presence of spillovers. In other words, if countries believe that they can simply freeride on other countries' efforts, it will be difficult for the reduced long-term abatement cost benefit to serve as a meaningful justification for near-term deployment policies to promote currently expensive technologies.

\subsection{Long-term payoffs from early-mover advantages}

If the reduced long-term abatement benefit cannot provide sufficient incentive to justify near-term deployment policies, the question that arises is whether including other benefits of near-term deployment policies such as early-mover advantages changes the results obtained earlier and if not, how large should these benefits be, so that near-term deployment policies are fully justified. If the early-mover advantage benefit is included, the wind deployment strategy pays off (Figure 3) under all technological change scenarios. However, payoffs for the solar strategy continue to be less than one. 
To understand how large the early-mover advantage benefit should be, so that a near-term solar deployment strategy is fully justified, we calculate the breakeven fraction of the global market revenue generated by the sales of the solar technologies across the globe for a range of assumptions about the number of years for which early-mover advantages are assumed to exist (Figure 4).

For a solar deployment strategy to pay off, Chinese firms need to capture about half of the global solar market until 2100, assuming no spillovers (Figure 4). In the presence of spillovers, however, even if Chinese firms are able to capture up to $100 \%$ of the global solar market until 2100 , a solar deployment policy might not pay off. These results suggest that early-mover advantages can potentially provide substantial benefits, but only if these advantages are both strong and persistent. Although we do not investigate in detail, spillovers might dampen the early-mover advantage benefit by creating benefits to being "late-movers", rather than "early-movers" (Fudenberg and Tirole, 1985; Hoppe, 2000).

\subsection{Long-term payoffs in the presence of a technological breakthrough in solar technologies}

A key assumption that could influence the results presented thus far is the rate of technological change. We have assumed that solar technologies remain expensive even if deployment policies are assumed to lead to faster technological improvements. However, since solar technologies have shown the potential for rapid technological change recently, a particularly interesting scenario for investigation is one in which a solar deployment strategy leads to a technological breakthrough in solar technologies in the future (Figure 5) (REN21, 2015). ${ }^{11}$

In this case, the solar strategy pays off, even if payoffs from early-mover advantages are not included and irrespective of the choice of technology by the U.S. This is because, in this scenario, access to the "breakthrough" solar technologies (which are cheaper than wind in the long-term) leads to greater reductions in abatement costs and therefore, higher payoffs. As before, the payoffs are higher if the "breakthrough" technologies spill over to the rest of the world. These results suggest that in order for reduced long-term abatement costs to justify investments in higher-cost, emerging technologies, substantial improvement in those technologies will be important. Further, the wider these improvements are available, the greater the payoffs would be. ${ }^{12}$

\footnotetext{
${ }^{11}$ We do not consider the possibility of a breakthrough in wind technologies because such technologies are relatively mature compared to solar. Also, such a scenario would not give insights different from those derived from Figures 3 and 4.

${ }^{12}$ In the Supplementary information, we further show that these insights are found to be robust even when the stringency of the near-term deployment policies is relaxed.
} 


\section{Conclusions and Policy Implications}

This study examines the long-term benefits of near-term policies to promote the deployment of lowcarbon technologies in the context of climate mitigation. We highlight two types of benefits: reduced long-term abatement costs and early-mover advantages in the presence of a long-term global climate mitigation regime. A review of relevant literature shows that the magnitudes of such benefits could be influenced by complex interactions among a variety of country, sector or even technology specific factors. It is therefore important to effectively articulate and understand the context to be able to assess the potential, mitigation-based benefits of low-carbon deployment policies.

Our illustrative example highlights the importance of a combined international and domestic perspective in evaluations of the effectiveness of domestic low-carbon deployment policies in the context of climate change mitigation. Our results indicate that the potential to reduce future abatement costs might not be a sufficient incentive for countries to undertake policies to promote the deployment of low-carbon technologies, in particular, currently emerging and expensive technologies. Previous research has shown that an important consequence of such lack of incentive is a divergence between the domestic and global least-cost outcomes (Iyer et al., 2015b; Leibowicz et al., 2015). This suggests a role for international cooperation in low-carbon technology development and deployment to address the public goods characteristics of investments in technologies and associated opportunities to free-ride in the context of global climate change mitigation. Such cooperation will be all the more important to foster rapid technological change, which will be crucial to provide sufficient incentives to undertake investments in currently expensive technologies. In the specific case of climate mitigation, this argues for technology policies that seek to create a broad portfolio internationally, especially in the areas of currently more undeveloped technologies. This is particularly important since, at the level of individual countries, pursuing such technologies is harder to justify alone. This might include, for example, encouraging the development of next-generation solar, biofuel, or carbon capture and storage technologies.

Our analysis also suggests that early-mover advantages can provide an important incentive to undertake low-carbon deployment policies, even in a competitive framework. However, the potential benefits depend strongly on how much of the global market for the targeted technologies countries can capture and for how long. The history of the Danish wind industry shows that market leadership is not eternal. More broadly, our research suggests that successful decision-making with regards to low-carbon technology investment strategies will involve a careful assessment of the technologies under question, the scope for technological improvements, nature of spillovers and domestic as well as international energy system characteristics, policy and institutional environments. 


\section{Acknowledgements}

Research support for G.C.I., L.E.C. and J.A.E. was provided by the Global Technology Strategy Program. N.E.H. was supported by the National Science Foundation under grant number 1056998. The authors are grateful to the anonymous reviewers for their valuable comments and suggestions. The views and opinions expressed in this paper are those of the authors alone.

\section{References}

Ades, A., Tella, R.D., 1997. National Champions and Corruption: Some Unpleasant Interventionist Arithmetic. The Economic Journal 107, 1023-1042.

Anadon, L.D., Bunn, M., Chan, G., Chan, M., Jones, C., Kempener, R., Lee, A., Logar, N., Narayanamurti, V., 2011. Transforming U.S. Energy Innovation Belfer Center for Science and International Affairs, Harvard Kennedy School (2011).

Arrow, K., 1962. The economic implications of learning by doing. The review of economic studies 29 , 155-173.

Barradale, M.J., 2010. Impact of public policy uncertainty on renewable energy investment: Wind power and the production tax credit. Energy Policy 38, 7698-7709.

Bernard, A.B., Jensen, J.B., Lawrence, R.Z., 1995. Exporters, jobs, and wages in US manufacturing: 1976-1987. Brookings Papers on Economic Activity. Microeconomics 1995, 67-119.

Black \& Veatch, 2012. Cost and Performance Data for Power Generation Technologies Prepared for the National Renewable Energy Laboratory by Black \& Veatch (2012).

Blazejczak, J., Braun, F.G., Edler, D., Schill, W.-P., 2014. Economic effects of renewable energy expansion: A model-based analysis for Germany. Renewable and Sustainable Energy Reviews 40, 10701080.

Böhringer, C., Keller, A., van der Werf, E., 2013. Are green hopes too rosy? Employment and welfare impacts of renewable energy promotion. Energy Economics 36, 277-285.

Borenstein, S., 2012. The Private and Public Economics of Renewable Electricity Generation. Journal of Economic Perspectives 26, 67-92.

Bowen, A., Fankhauser, S., 2011. The green growth narrative: Paradigm shift or just spin? Global Environmental Change 21, 1157-1159.

Braun, F.G., Schmidt-Ehmcke, J., Zloczysti, P., 2010. Innovative Activity in Wind and Solar Technology: Empirical Evidence on Knowledge Spillovers Using Patent Data, CEPR Discussion Paper Series 7865.

Bresnahan, T.F., 2010. General purpose technologies. Handbook of the Economics of Innovation 2, 761791.

Bresnahan, T.F., Trajtenberg, M., 1995. General purpose technologies 'Engines of growth'? Journal of econometrics 65, 83-108. 
Clarke, J.F., Edmonds, J., 1993. Modelling energy technologies in a competitive market. Energy Economics 15, 123-129.

Clarke, L., Calvin, K., Edmonds, J., Kyle, P., Wise, M., 2010. When Technology and Climate Policy Meet: Energy Technology in an International Policy Context, in: Aldy, J.E., Stavins, R.N. (Eds.), PostKyoto International Climate Policy: Implementing Architectures for Agreement: Research from the Harvard Project on International Climate Agreements. Cambridge University Press, Cambridge, UK.

Clarke, L., Edmonds, J., Jacoby, H., Pitcher, H., Reilley, J., Richels, R., 2007. Scenarios of Greenhouse Gas Emissions and Atmospheric Concentrations. Sub-report 2.1A of Synthesis and Assessment Product 2.1 by the U.S. Climate Change Science Program and the Subcommittee on Global Change Research, Department of Energy, Office of Biological and Environmental Research, Washington, DC.

Clarke, L., Jiang, K., Akimoto, K., Babiker, M., Blanford, G., Fisher-Vanden, K., Hourcade, J.-C., Krey, V., Kriegler, E., Löschel, A., McCollum, D., Paltsev, S., Rose, S., Shukla, P.R., Tavoni, M., van der Zwaan, B.C.C., van Vuuren, D.P., 2014. Assessing Transformation Pathways, in: Edenhofer, O., PichsMadruga, R., Sokona, Y., Farahani, E., Kadner, S., Seyboth, K., Adler, A., Baum, I., Brunner, S., Eickemeier, P., Kriemann, B., Savolainen, J., Schlömer, S., von Stechow, C., Zwickel, T., Minx, J.C. (Eds.), Climate Change 2014: Mitigation of Climate Change. Contribution of Working Group III to the Fifth Assessment Report of the Intergovernmental Panel on Climate Change. Cambridge University Press, Cambridge, United Kingdom and New York, NY, USA.

Clarke, L., Weyant, J.P., 2002. Modeling induced technological change: an overview, in: Arnulf, G., Nebojsa, N., D., N.W. (Eds.), Technological Change and the Environment. Resources for the Future, Washington, DC, USA, pp. 320-363.

Clarke, L., Weyant, J.P., Edmonds, J., 2008. On the sources of technological change: What do the models assume? Energy Economics 30, 409-424.

Council of Economic Advisers, 2014. The economic impact of the American Recovery and Reinvestment Act.https://www.whitehouse.gov/sites/default/files/docs/cea_arra_report.pdf.July 30,2015

Edmonds, J., Clarke, J., Dooley, J., Kim, S., Smith, S., 2004. Stabilization of $\mathrm{CO}_{2}$ in a B2 world: insights on the roles of carbon capture and disposal, hydrogen, andtransportation technologies. Energy Economics $26,517-537$.

Edmonds, J., Reilly, J., 1985. Global energy: assessing the future. Oxford University Press, Oxford, U.K.

Eisen, J.B., 2011. New Energy Geopolitics: China, Renewable Energy, and the Greentech Race. ChicagoKent Law Review 86.

Fankhauser, S., Bowen, A., Calel, R., Dechezleprêtre, A., Grover, D., Rydge, J., Sato, M., 2013. Who will win the green race? In search of environmental competitiveness and innovation. Global Environmental Change 23, 902-913.

Fudenberg, D., Tirole, J., 1985. Preemption and Rent Equalization in the Adoption of New Technology. The Review of Economic Studies 52, 383-401.

Galiana, I., Green, C., 2009. Let the global technology race begin Nature 46, 570-571.

GCAM-wiki, http://wiki.umd.edu/gcam/index.php?title=Main_Page.November 24,2014 
Goulder, L.H., Mathai, K., 2000. Optimal CO2 Abatement in the Presence of Induced Technological Change. Journal of Environmental Economics and Management 39, 1-38.

Grubb, M., 1997. Technologies, energy systems and the timing of $\mathrm{CO}_{2}$ emissions abatement: An overview of economic issues. . Energy policy 25, 159-172.

Grübler, A., 2010. The costs of the French nuclear scale-up: A case of negative learning by doing. Energy Policy 38, 5174-5188.

Grübler, A., Messner, S., 1998. Technological change and the timing of mitigation measures. Energy Economics 20, 495-512.

Grubler, A., Nemet, G., 2012. Sources and Consequences of Knowledge Depreciation. Historical Case Studies of Energy Technology Innovation, in: A., G., Aguayo, F., Gallagher, K.S., Hekkert, M., Jiang, K., Mytelka, L., Neij, L., Nemet, G., Wilson, C. (Eds.), Global Energy Assessment. Cambridge University Press, Cambridge, UK.

Hansen, J.D., Jensen, C., Madsen, E.S., 2003. The establishment of the Danish windmill industry—Was it worthwhile? Review of World Economics 139, 324-347.

Hidalgo, C.A., Klinger, B., Barabási, A.L., Hausmann, R., 2007. The product space conditions the development of nations. Science 317, 482-487.

Hoppe, H.C., 2000. Second-mover advantages in the strategic adoption of new technology under uncertainty. International Journal of Industrial Organization 18, 315-338.

Hoppmann, J., Peters, M., Schneider, M., Hoffmann, V.H., 2013. The two faces of market support—How deployment policies affect technological exploration and exploitation in the solar photovoltaic industry. Research Policy 42, 989-1003.

Huberty, M., Gao, H., Mandell, J., Zysman, J., 2011. Shaping the Green Growth Economy: a review of the public debate and the prospects for green growth. The Berkeley Roundtable on the International Economy., .

IEA, 2009. Ensuring Green Growth in a Time of Economic Crisis: The Role of Energy

Technology.http://www.iea.org/publications/freepublications/publication/ensuring_green_growth.pdf.July 30,2015

IPCC, 2014. Climate Change 2014: Synthesis Report. Contribution of Working Groups I, II and III to the Fifth Assessment Report of the Intergovernmental Panel on Climate Change, in: Pachauri, R.K., Meyer, L.A. (Eds.). Intergovernmental Panel on Climate Change, Geneva, Switzerland.

IRENA, 2014a. Renewable energy and jobs.http://www.irena.org/Publications/rejobs-annual-review2014.pdf.July 30,2015

IRENA, 2014b. Evaluating renewable energy policy: A review of criteria and indicators for assessment.

Iyer, G., Clarke, L., Edmonds, J., Flannery, B., Hultman, N., McJeon, H., Victor, D.G., 2015a. Improved Representation of Investment Decisions in Assessments of $\mathrm{CO}_{2}$ Mitigation. Nature Climate Change 5, 436-440.

Iyer, G., Clarke, L., Edmonds, J., Hultman, N., McJeon, H., 2015b. Long-term payoffs of near-term lowcarbon deployment policies Energy Policy 86, 493-505. 
Iyer, G., Hultman, N., Eom, J., McJeon, H., Patel, P., Clarke, L., 2015c. Diffusion of low-carbon technologies and the feasibility of long-term climate targets. Technological Forecasting and Social Change. 90, Part A, 103-118.

Iyer, G.C., Edmonds, J.A., Fawcett, A.A., Hultman, N.E., Alsalam, J., Asrar, G.R., Calvin, K.V., Clarke, L.E., Creason, J., Jeong, M., Kyle, P., 2015d. The contribution of Paris to limit global warming to $2^{\circ} \mathrm{C}$ Environmental Research Letters 10, 125002.

Kahouli-Brahmi, S., 2008. Technological learning in energy-environment-economy modelling: A survey. Energy Policy 36, 138-162.

Kammen, D.M., Kapadia, K., Fripp, M., 2004. Putting Renewables to Work: How Many Jobs Can the Clean Energy Industry Generate? . RAEL Report, University of California, Berkeley.

Karp, L., Stevenson, M., 2012. Green Industrial Policy: Trade and Theory.http://www.greengrowthknowledge.org/sites/default/files/downloads/resource/Green_industrial_p olicy_trade_and_theory_Ggkp.pdf.30 July 2015

Kim, S., Edmonds, J., Lurz, J., Smith, S., Wise, M., 2006. The ObjECTS framework for integrated assessment: hybrid modeling of transporation. . Energy Journal 27, 63-91.

Koomey, J., Hultman, N.E., 2007. A reactor-level analysis of busbar costs for US nuclear plants, 19702005. Energy Policy 35, 5630-5642.

Krueger, A.O., 1974. The political economy of the rent-seeking society. The American economic review 64, 291-303.

Krugman, P., 1987. The narrow moving band, the Dutch disease, and the competitive consequences of Mrs. Thatcher: Notes on trade in the presence of dynamic scale economies. Journal of development Economics 27, 41-55.

Lambert, R.J., Silva, P.P., 2012. The challenges of determining the employment effects of renewable energy. Renewable and Sustainable Energy Reviews 16, 4667-4674.

Lehr, U., Lutz, C., Edler, D., 2012. Green jobs? Economic impacts of renewable energy in Germany. Energy Policy 47, 358-364.

Leibowicz, B.D., Krey, V., Grubler, A., 2015. Representing spatial technology diffusion in an energy system optimization model. Technological Forecasting and Social Change.

Lieberman, M.B., Montgomery, D.B., 1988. First-mover advantages. Strategic Management Journal 9, 41-58.

McFadden, D., 1980. Econometric models for probabilistic choice among products. The Journal of Business 53, S13-S29.

McJeon, H.C., Clarke, L., Kyle, P., Wise, M., Hackbarth, A., Bryant, B.P., Lempert, R.J., 2011.

Technology interactions among low-carbon energy technologies: What can we learn from a large number of scenarios? Energy Economics 33, 619-631.

Meinshausen, M., Raper, S.C.B., Wigley, T.M.L., 2011. Emulating coupled atmosphere-ocean and carbon cycle models with a simpler model, MAGICC6 - Part 1: Model description and calibration. Atmospheric Chemistry and Physics 11, 1417-1456. 
Milliman, S.R., Prince, R., 1989. Firm incentives to promote technological change in pollution control. Journal of Environmental economics and Management 17, 247-265.

Mundaca, L., Luth Richter, J., 2015. Assessing 'green energy economy' stimulus packages: Evidence from the U.S. programs targeting renewable energy. Renewable and Sustainable Energy Reviews 42, 1174-1186.

Nemet, G.F., 2006. Beyond the learning curve: factors influencing cost reductions in photovoltaics. Energy Policy 34, 3218-3232.

Nemet, G.F., 2009. Demand-pull, technology-push, and government-led incentives for non-incremental technical change. Research Policy 38, 700-709.

OECD, 2011. Towards green growth: Summary for policy makers.http://www.oecd.org/greengrowth/48012345.pdf.July 30,2015

REN21, 2015. Renewables 2015: Global Status Report.

Rodrik, D., 2006. Industrial policy for the twenty-first century.https://www.sss.ias.edu/files/pdfs/Rodrik/Research/industrial-policy-twenty-first-century.pdf.July 30,2015

Sands, R., Leimbach, M., 2003. Modeling agriculture and land use in an integrated assessment framework Climatic Change 56, 185-210.

Schneider, S.H., Goulder, L.H., 1997. Achieving low-cost emissions targets. Nature 389, 13-14.

The Economist, 2015. Whose oil in Brazil?http://www.economist.com/news/americas/21643224-onemany-casualties-petrobras-scandal-misguided-industrial-policy-whose-oil.July 30,2015

The PEW Charitable Trusts, 2015. Power Shifts: Emerging Clean Energy Markets.http://www.pewtrusts.org/ /media/Assets/2015/05/Emerging-Markets-Report_WEB.pdf.July 30,2015

Train, K., 1993. Qualitative choice analysis: theory, econometrics, and an application to automobile demand MIT Press.

UNEP, 2008. Green Jobs: Towards decent work in a sustainable, low-carbon world. UNEP/ILO/IOE/ITUC.

UNEP, 2015. China's Pathway to a Green

Economy.http://www.unep.org/greeneconomy/AdvisoryServices/China/tabid/56270/Default.aspx.July 30,2015

UNFCCC, 2015. INDCs as communicated by Parties.http://www4.unfccc.int/submissions/indc/Submission\%20Pages/submissions.aspx.July 30,2015

Victor, D.G., Yanosek, K., 2011. Crisis in Clean Energy: Stark Realities of the Renewables Craze. Foreign Affairs 90, 112-120.

Voituriez, T., Balmer, B., 2012. The Muddle over Green

Race.http://www.iddri.org/Publications/Collections/Analyses/STUDY0112_TV\%20BB_green\%20race.p df.July 30,2015 
von Stechow, C., McCollum, D., Riahi, K., Minx, J.C., Kriegler, E., van Vuuren, D.P., Jewell, J., Robledo-Abad, C., Hertwich, E., Tavoni, M., Mirasgedis, S., Lah, O., Roy, J., Mulugetta, Y., Dubash, N.K., Bollen, J., Ürge-Vorsatz, D., Edenhofer, O., 2015. Integrating Global Climate Change Mitigation Goals with Other Sustainability Objectives: A Synthesis. Annual Review of Environment and Resources 40, 363-394.

Wagner, J., 2007. Exports and Productivity: A Survey of the Evidence from Firm-level Data. The World Economy 30, 60-82.

Wigley, T.M., 2008. MAGICC/SCENGEN 5.3: User Manual Version 2 NCAR.

Wigley, T.M., Raper, S.C.B., 1992. Implications for climate and sea level of revised IPCC emissions scenarios. Nature 357, 293-300. 
Table 1. Summary of factors influencing long-term benefits of near-term low-carbon deployment policies

\begin{tabular}{|c|c|c|c|}
\hline \multirow{2}{*}{ Factor category } & \multirow{2}{*}{ Key factors } & \multicolumn{2}{|c|}{ Expected impact on long-term benefits (ceterus paribus) } \\
\hline & & Reduced abatement costs & Early-mover advantages \\
\hline $\begin{array}{l}\text { Potential for technological } \\
\text { change }\end{array}$ & $\begin{array}{l}\text { Maturity of targeted } \\
\text { technology }\end{array}$ & Higher benefits for currently immature technologies beca & use they have greater potential for technological change \\
\hline \multirow{5}{*}{$\begin{array}{l}\text { Rate and direction of } \\
\text { technological change }\end{array}$} & $\begin{array}{l}\text { Amount of near-term } \\
\text { deployment }\end{array}$ & \multicolumn{2}{|c|}{ Higher benefits with higher amount of near-term deployment } \\
\hline & Technological spillovers & \multicolumn{2}{|c|}{$\begin{array}{l}\text { Higher or lower benefits depending on the nature of spillovers from outside the domain of the targeted } \\
\text { technology and their interaction with the targeted technology }\end{array}$} \\
\hline & Market forces & \multicolumn{2}{|c|}{ Higher or lower benefits depending on changes in downstream or upstream markets } \\
\hline & $\begin{array}{l}\text { Impact of deployment policies } \\
\text { on innovation }\end{array}$ & \multicolumn{2}{|c|}{ Lower benefits if deployment policies reduce innovation } \\
\hline & Stability of policy incentives & \multicolumn{2}{|c|}{ Lower benefits if policy incentives are not steady over time } \\
\hline $\begin{array}{l}\text { Public goods characteristics of } \\
\text { emissions abatement and } \\
\text { technological change }\end{array}$ & Public goods characteristics & $\begin{array}{l}\text { Higher or lower benefits depending on relative } \\
\text { magnitudes of free-riding opportunities and impacts on } \\
\text { long-term marginal abatement costs }\end{array}$ & $\begin{array}{l}\text { Lower benefits if free-riding opportunities create } \\
\text { incentives to be late-movers rather than early-movers }\end{array}$ \\
\hline \multirow{2}{*}{$\begin{array}{l}\text { Factors directly influencing the } \\
\text { magnitude of early-mover } \\
\text { advantages }\end{array}$} & Existing capabilities & \multirow{2}{*}{ NA } & $\begin{array}{l}\text { Higher benefits for countries with better existing } \\
\text { capabilities }\end{array}$ \\
\hline & $\begin{array}{l}\text { Emergence of international } \\
\text { competitors }\end{array}$ & & Lower benefits with more international competition \\
\hline
\end{tabular}


Table 2 Summary of key assumptions

\begin{tabular}{|c|c|c|}
\hline Variable & Near-term & Long-term \\
\hline Period & 2016-2030 & Global carbon price \\
\hline Policy mechanism & $\begin{array}{c}\text { Deployment policy (renewable } \\
\text { portfolio standard) }\end{array}$ & N50 ppm CO 2 e by 2100 \\
\hline Policy stringency & $\begin{array}{c}500 \mathrm{GW} \text { cumulative installed } \\
\text { capacity by 2030 }\end{array}$ & NA \\
\hline Near-term Costs & $\begin{array}{c}\text { Change in consumer and producer } \\
\text { surplus due to policy }\end{array}$ & $\begin{array}{c}\text { Reduced long-term abatement costs } \\
\text { Early-mover advantages }\end{array}$ \\
\hline $\begin{array}{c}\text { Long-term benefits } \\
\text { Technological } \\
\text { change }\end{array}$ & $\begin{array}{c}\text { Deployment policies do not lead to } \\
\text { additional technological change }\end{array}$ & Technological change scenarios $^{\mathrm{d}}$ \\
\hline
\end{tabular}

${ }^{a}$ See Supplementary information for a sensitivity on the stringency of the near-term deployment policy

${ }^{\mathrm{b}}$ Abatement costs are calculated as area under the marginal abatement cost curve

${ }^{\mathrm{c}}$ Early-mover advantages are calculated as a fraction of global market revenue generated by the sales of the targeted technology across the globe

${ }^{\mathrm{d}}$ See Table 3 
Table 3 Technological change scenarios ${ }^{a}$

\begin{tabular}{|c|c|c|}
\hline Technological change scenario & \multicolumn{2}{|c|}{ Technology costs in the long-term } \\
Near-term deployment policy leading to & $\begin{array}{c}\text { Region with deployment } \\
\text { policy }\end{array}$ & $\begin{array}{c}\text { Region without } \\
\text { deployment policy }\end{array}$ \\
\hline No additional technological change & Reference & Reference \\
\hline $\begin{array}{c}\text { Faster domestic technological } \\
\text { improvements }\end{array}$ & Advanced & Reference \\
\hline $\begin{array}{c}\text { Faster technological improvements and } \\
\text { delayed spillovers }\end{array}$ & Advanced \\
\hline $\begin{array}{c}\text { Faster technological improvements and } \\
\text { immediate spillovers }\end{array}$ & Advanced & Advanced \\
\hline
\end{tabular}

${ }^{\mathrm{a}}$ Technology costs are represented as exponential functions of time. This representation is largely agnostic to the specific mechanism through which technological change occurs (Clarke et al., 2008; Clarke et al., 2006). Costs of advanced technologies decrease at higher rates compared to reference technologies. In scenarios with delayed spillovers, the cost trajectory follows the reference cost trajectory for fifteen years and then diverges with an accelerated rate of improvement, asymptotically approaching advanced technology costs (Figure SI-1, Table SI-1). 
Table 4 Near-term deployments, abatements and costs

\begin{tabular}{|c|c|c|c|c|c|c|c|}
\hline & & \multicolumn{3}{|c|}{ China } & \multicolumn{3}{|c|}{ USA } \\
\hline & & $\begin{array}{l}\text { Without Deployment } \\
\text { Policy }\end{array}$ & $\begin{array}{l}\text { Wind } \\
\text { Policy }\end{array}$ & $\begin{array}{l}\text { Solar } \\
\text { Policy }\end{array}$ & $\begin{array}{l}\text { Without Deployment } \\
\text { Policy }\end{array}$ & $\begin{array}{l}\text { Wind } \\
\text { Policy }\end{array}$ & $\begin{array}{l}\text { Solar } \\
\text { Policy }\end{array}$ \\
\hline \multirow{2}{*}{$\begin{array}{c}2030 \text { Installed capacity } \\
\text { [GW] }\end{array}$} & Wind & 177 & 500 & 114 & 62 & 500 & 46 \\
\hline & Solar & 11 & 7 & 500 & 4 & 5 & 500 \\
\hline \multicolumn{2}{|c|}{$\begin{array}{l}\text { 2016-2030 cumulative } \mathrm{CO}_{2} \text { emissions } \\
\text { abatement relative to the baseline } \\
\qquad\left[\mathrm{MtCO}_{2}\right]\end{array}$} & 0 & 1327 & 3157 & 0 & 1389 & 3153 \\
\hline \multicolumn{2}{|c|}{$\begin{array}{l}\text { 2016-2030 NPV of costs } \\
\text { [2012 Billion USD] }\end{array}$} & 0 & 168 & 880 & 0 & 334 & 1150 \\
\hline
\end{tabular}




\section{NEAR-TERM}

Domestic low-carbon deployment policies

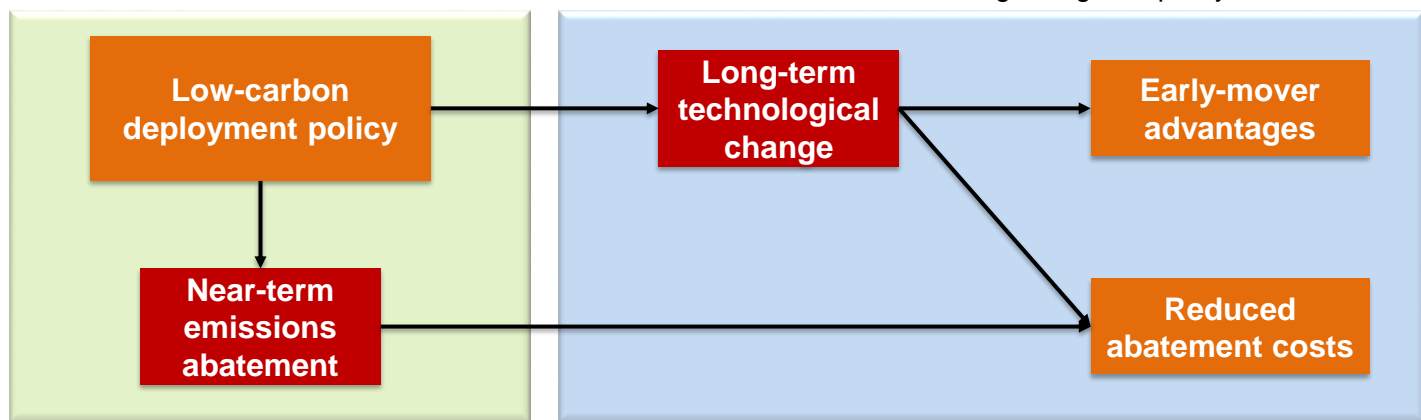

Figure 1 Examples of long-term benefits of near-term low-carbon deployment policies in the context

of climate change mitigation (Iyer et al., 2015b).

\section{LONG-TERM}

Global climate change mitigation policy chrm hnological ange 


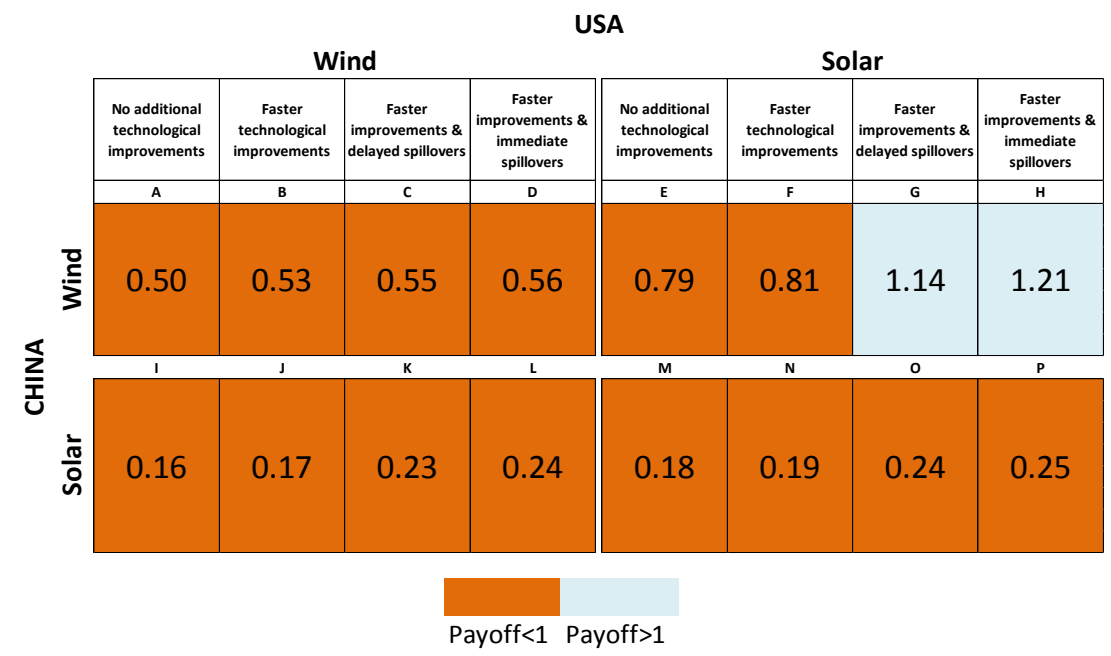

Figure 2 China's payoffs from reduced long-term abatement costs alone, under central technology cost assumptions (Table SI-1). 


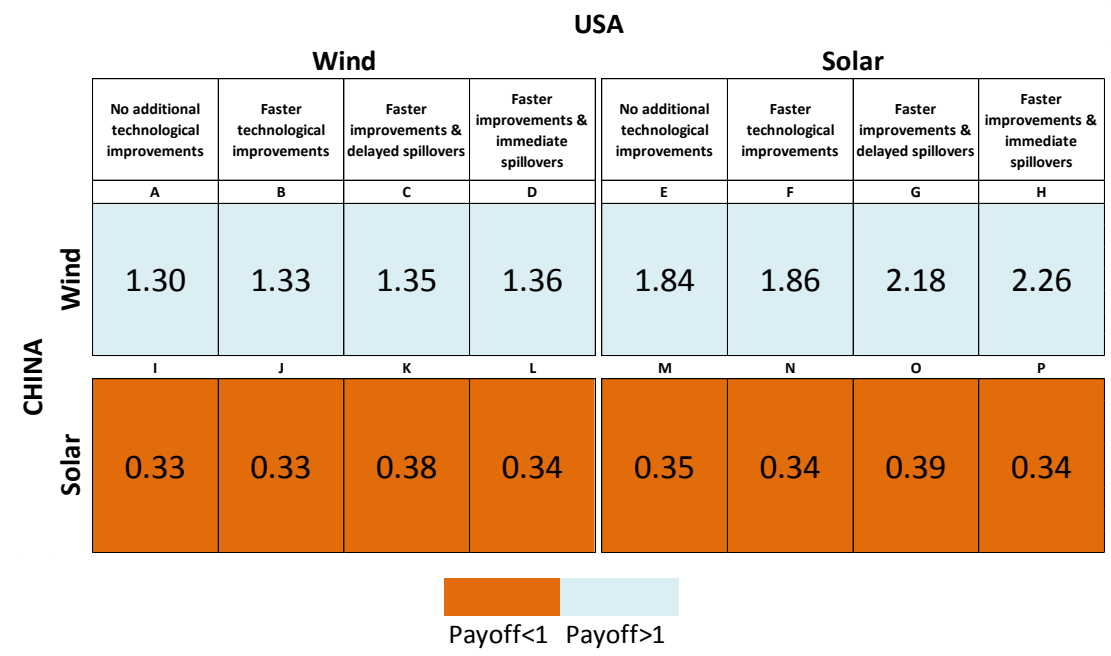

Figure 3 China's payoffs from reduced long-term abatement costs and early-mover advantages under central technology cost assumptions (Table SI-1). Early-mover advantages in this figure are calculated as 30\% of global market revenue for 20 years from 2030 (that is, until 2050). 


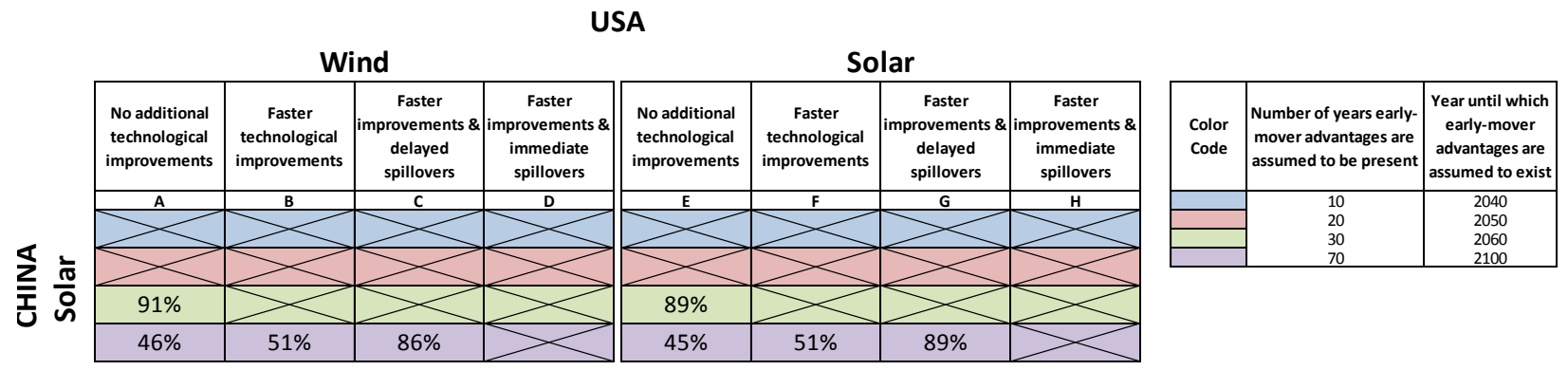

Figure 4 The breakeven fraction of global market revenue from sales of solar technologies that would result in China's total payoffs from reduced long-term abatement costs and early-mover advantages to be equal to one. The cells are color coded according to the number of years early-mover advantages are assumed to be present (legend on the right). A fraction greater than $100 \%$ is infeasible; such values are indicated by an " $X$ ". 


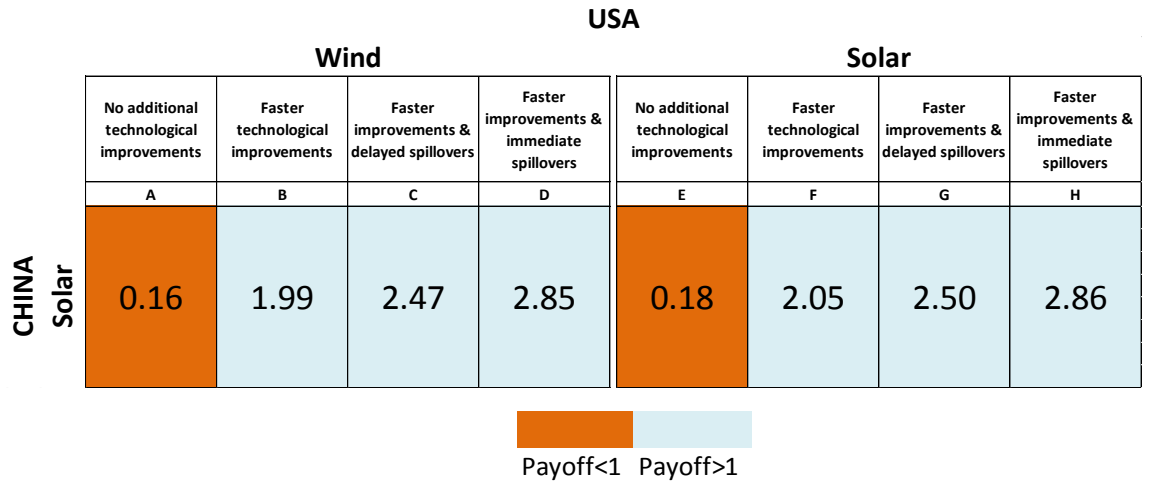

Figure 5 China's payoffs from reduced long-term abatement costs with a solar deployment strategy assuming that promoting the deployment of solar leads to a technological breakthrough in solar technologies. 